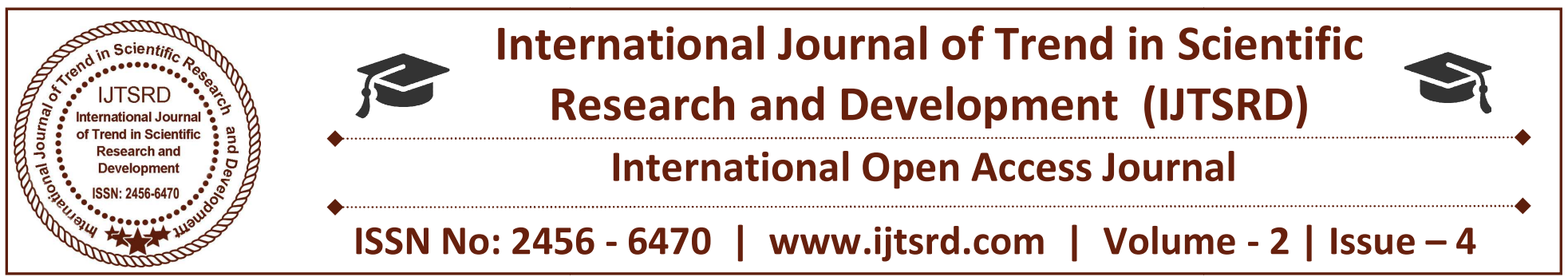

\title{
Effect of Static Load on Cast Iron Drainage Manhole Cover
}

\author{
Dhruvkumar Joshi, Hardik C. Tekwani \\ Assistant Professor, Mechanical Engineering Department, \\ Vadodara Institute of Engineering, Kotambi, Vadodara, Gujarat, India
}

\begin{abstract}
Drainage manhole covers are widely used in sanitary sewer and storm water systems in world. However, technical information regarding their structural aspects is limited. The main objective of this paper is to evaluate the effect of main parameters that impact the design of manhole cover. A three-dimensional finite element model for circular manhole cover was developed using AutoCAD, solid works and NX. The 3d model was analyzed by ANSYS for different parameters like different load and different material. Here cast iron is used as material of cover. The load condition was applied for two type of cover one without stiffer and with stiffer.
\end{abstract}

Keywords: Drainage manhole cover, stiffer, UDL, static load, deformation etc

\section{INTRODUCTION}

Manholes are used for inspection of the drainage lines and periodic maintenance. These manholes can be a cast in place or precast design. A new design for mainline manholes has recently been considered that should ease installation and reduce installation costs. This design is called a type " $\mathrm{T}$ ' manhole. Type " $\mathrm{T}$ " manholes are fabricated by the concrete pipe manufacturers and are constructed to be part of the pipe. This type of manhole is a pre-cast design that is delivered to the site and set in place. An advantage to the type " $\mathrm{T}$ ' manhole is a much more efficient hydraulic design than that of the Colorado Standard Design and construction time is reduced over the standard design. A manhole is a precast steel reinforced concrete manhole. The advantages of a manhole are that they can, be delivered to the site and set in place more easily than the standard box base, saving construction time thus using less time for lane closure when this is an important factor and they are more efficient hydraulically than the box base manhole being that the manhole is a part of the pipe itself. However, even with the believed ease of construction, improved hydraulic efficiency, and reduced cost the actual structural performance of the finished manhole in place must be evaluated.

\section{A. History}

Pre-1940s: The need for cast iron construction castings was met by local foundries. Castings were made from gray iron. Nearly every town had its own foundry, and each foundry had its own designs. Usually the foundries did not complete in-depth loading calculations. Rather, casting design was an educated guess based on trial and error, so adding a safety factor consisted of adding more iron. This is one reason why many old cover designs are so heavy - when in doubt, more material was added. Post1940s: - H-20 Loading: American Association of State Highway Transportation Officials (AASHTO) published its bridge design criteria, commonly known as H-20 or HS-20. It consists of truck axle loading of $32,000 \mathrm{lbs}$, or wheel loading of $16,000 \mathrm{lbs}$. This design criteria did NOT specifically address loading on construction castings, but due to casting size, usually only one tire can be on a casting at a time. When contractors ask for H-20 or HS-20 loading, they are asking only for a casting to meet the design criteria of 16,000 lbs. If they do not ask for a safety factor in construction castings, they may not get the quality they are expecting. 


\section{B. Drainage manhole cover}

Every manhole cover, from the simplest to the most ornate, is first modeled in wood or aluminum. The model is used to make the mold into which the molten cast iron will be poured. The designs that have been created for the surface of the manholes are as varied as the skilled artisans who created them. All manhole covers are round because a round object cannot be dropped into a round hole of the same diameter. This is vital since the weight of the manhole could easily kill a worker standing underneath it.

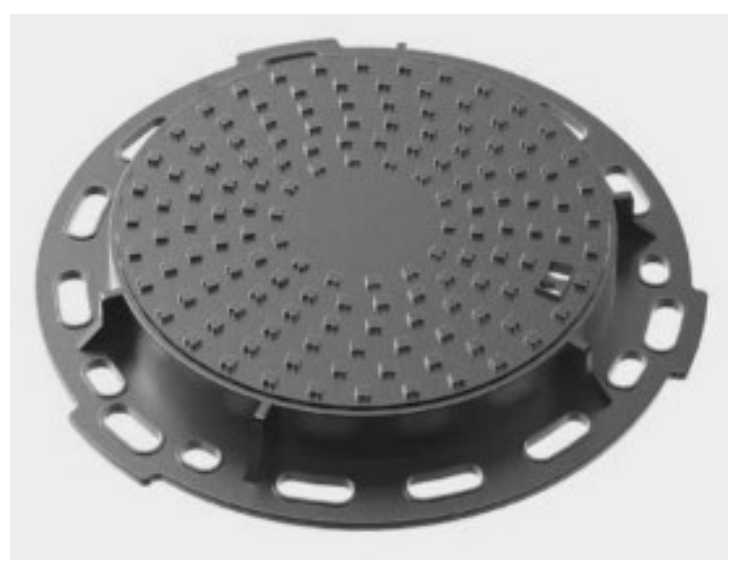

Figure 1: Manhole of ductile cast iron

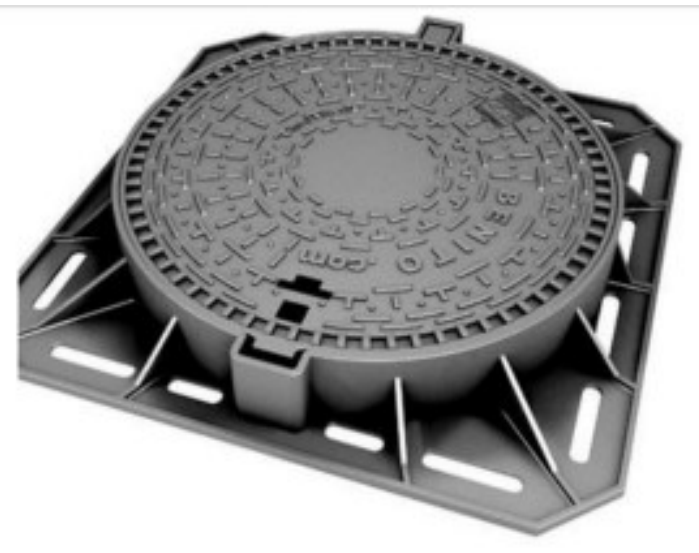

Figure 2: Manhole of ISO 1083

\section{LITRATURE REVIEW}

[1] David A. Price Colorado Department of Transportation [1] The Type $\mathrm{T}^{\prime}$ manhole was placed on Hampden Ave. with little difficulty in construction and minimal disruption to traffic flow. The two main advantages to a Type $T^{\prime}$ manhole is the ease of placement allowing quicker installation and thereby causing less traffic congestion and increasing overall safety on heavily traveled roadways. In 1992 the Type $\mathrm{T}^{\prime}$ manhole design was added to the CDOT Standard Plans. The two types of manholes discussed are shown in appendix B from the M\&S Standards M604-20.
[2] Chang Y, National Chiayi University, Department of Marketing and Logistics/Transportation, Chia-Yi, Taiwan. [2] To reduce the effects and potential risks from the manhole covers, highway authorities not only need to make sure that any newly installed manhole covers are as level as possible but also need to regularly maintain all the manhole covers to ensure that they are in good condition.

[3] Pete DeHaan, District manager, Corporate Accounts with EJ, East Jordan, Mich[3] Pre-1940s: The need for cast iron construction castings was met by local foundries. Castings were made from gray iron. Nearly every town had its own foundry, and each foundry had its own designs. Usually the foundries did not complete in-depth loading calculations. Rather, casting design was an educated guess based on trial and error, so adding a safety factor consisted of adding more iron. This is one reason why many old cover designs are so heavy when in doubt, more material.

H-20 Loading: American Association of State Highway Transportation Officials (AASHTO) published its bridge design criteria, commonly known as H-20 or HS-20. It consists of truck axle loading of $32,000 \mathrm{lbs}$, or wheel loading of $16,000 \mathrm{lbs}$. This design criterion did NOT specifically address loading on construction castings, but due to casting size, usually only one tire can be on a casting at a time. When contractors ask for H-20 or HS-20 loading, they are asking only for a casting to meet the design criteria of $16,000 \mathrm{lbs}$. If they do not ask for a safety factor in construction castings, they may not get the quality they are expecting.

[4]Materials Composite products shall be manufactured from fiber reinforced polymer (FRP). It shall consist of a FRP matrix consisting of between $45 \%$ to $70 \%$ fiber reinforcement by weight. Fiber reinforcement shall consist of fiberglass, carbon, agamid, basalt and/or natural fibers. The polymer matrix shall be thermoses consisting of a polyester, vinyl ester, epoxy, polyurethane, and/or hybrid chemical composition. The resin matrix must be thermo set. Manufacture Composite frames and covers shall be of uniform quality, with a dimensional tolerance of $1 / 16$ of an inch. The finished product will feature strength to weight ratio of $750: 1$. There shall be no possibility of corrosion welding between the cover and the frame, preventing damage to the infrastructure when opening. Gasket system shall be integrated to reduce traffic shock and abatement of noise and malodors. Static Coefficient of Friction 
shall be 0.6 or greater, as described in ASTM C1028 Standard, in both wet and dry applications. [4]

\section{METHODOLOGY}

5.1 CAD Geometry cad geometry gives a visualizing to the maker before production. Also cad geometry can use for various analysis in various software such as stress analysis CFD analysis vibration analysis. There are lots of modeling software to make cad geometry such as

\section{Solid works}

\section{$2 \mathrm{Nx}$ Siemens}

5.2 Mesh Generation ANSYS Meshing is a generalpurpose, intelligent, automated high-performance product. It produces the most appropriate mesh for accurate, efficient multi physics solutions. A mesh well suited for a specific analysis can be generated with a single mouse click for all parts in a model. Full controls over the options used to generate the mesh are available for the expert user who wants to finetune it. The power of parallel processing is automatically used to reduce the time you have to wait for mesh generation. Creating the most appropriate mesh is the foundation of engineering simulations. ANSYS Meshing is aware of the type of solutions that will be used in the project and has the appropriate criteria to create the best suited mesh. ANSYS Meshing is automatically integrated with each solver within the ANSYS Workbench environment. For a quick analysis or for the new and infrequent user, a usable mesh can be created with one click of the mouse. ANSYS Meshing chooses the most appropriate options based on the analysis type and the geometry of the model. Especially convenient is the ability of ANSYS Meshing to automatically take advantage of the available cores in the computer to use parallel processing and thus significantly reduce the time to create a mesh. Parallel meshing is available without any additional cost or license requirements.[6]

8.2 FEA analysis of drainage manhole cover without stiffener Stiffeners are secondary plates or sections which are attached to beam webs or flanges to stiffen them against out of plane deformations. Almost all main bridge beams will have stiffeners. However, most will only have transverse web stiffeners, i.e. vertical stiffeners attached to the web.
Table1: UDL load data

\begin{tabular}{|c|c|c|}
\hline \multicolumn{3}{|c|}{ UDL } \\
\hline p & 0.51863585 & $\mathrm{Mpa}$ \\
\hline OD & 850 & $\mathrm{~mm}$ \\
\hline $\mathrm{a}$ & 425 & $\mathrm{~mm}$ \\
\hline $\mathrm{t}$ & 40 & \\
\hline $\mathrm{v}$ & 0.3005 & \\
\hline E & 200000 & $\mathrm{Mpa}$ \\
\hline $\mathrm{D}$ & 1172548049 & \\
\hline & & \\
\hline
\end{tabular}

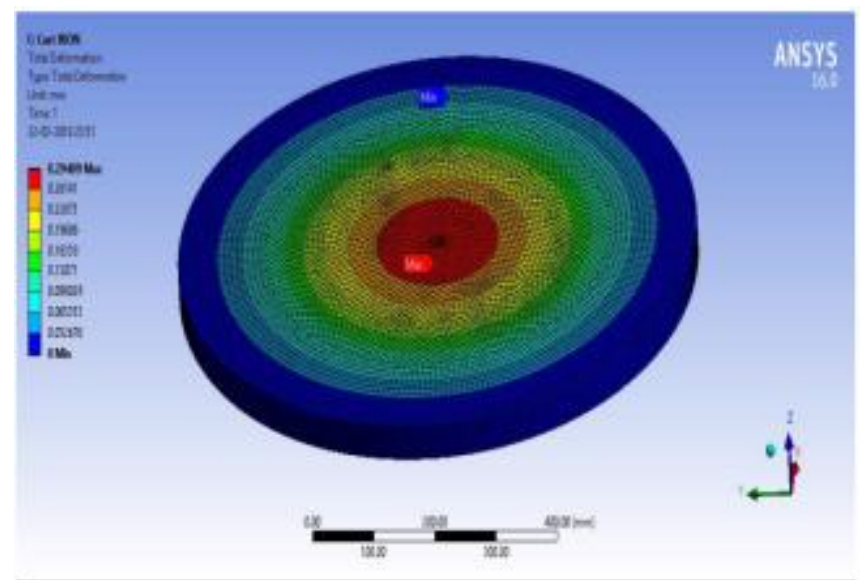

Figure 3: Cast iron drainage cover total deformation

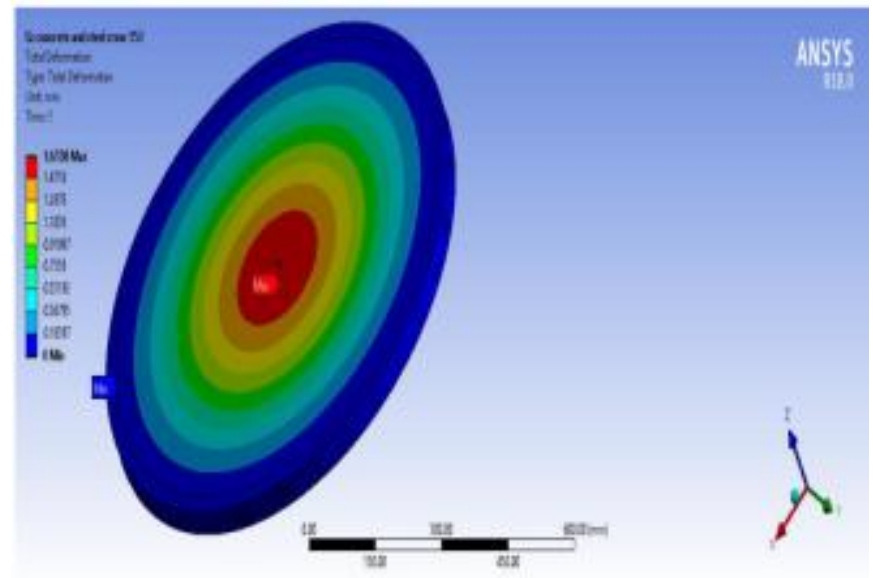

Figure 4: Total deformation of drainage manhole cover

\section{CONCLUSION}

During FEA analysis of two various geometry is under taken in case 1 stress analysis with stiffener and in case 2 without stiffener is done. Moreover various materials are also taken to predict results. However as a solution under a defined load is taken. And as a conclusion it is found that manhole cover with stiffener will be more durable and economical for production. Deformation is least in case of stiffener. After all analysis this work is at conclusion which is shown here. 
1. Drainage manhole cover with stiffener have less deformation compare to manhole cover without stiffener.

2. Mostly drainage manhole cover are seen without stiffener that's why it deforms very early in real situation and it can be also seen in FEA analysis.

3. But with stiffener the drainage manhole cover can stay stronger in real situation.

4. Deformation in drainage manhole cover with stiffener of cast iron is less than without stiffener.

5. Manhole cover with stiffener of cast iron have less strength than cover with material of concrete and cast iron

\section{References}

[1] https://www.codot.gov/programs/research/pdfs/19 93/manhole.pdf

[2] Analysis of effects of manhole covers on motorcycle driver maneuvers: a nonparametric classification tree approach.by Chang LY., Traffic Inj Prev., 2014.

[3] National Precast Concrete Association/ Precast Magazines / Precast Inc. Magazine / 2012 - MayJune / Manhole Frame and Cover Load Bearing Definitions / Manhole Frame and Cover Load Bearing Definitions

[4] Machining of Fibre Reinforced Plastic Composite Materials, by Alessandra Caggiano, Materials 2018, 11(3), MDPI,

[5] Composite Access Solutions Frames and Covers, http://americas.ejco.com/wcsstore/EJIWUSA

/EJIWAssets/Brochures\%20\&\%20Sell\%20Sheets

/Content_Composite\%20Access\%20Cove rs\%20and $\% 20$ Frames_0216.pdf

[6] https://www.ansys.com/enin/products/platform/ansys-meshing

[7] Static analysis: https://altairuniversity.com/ analysis/structural/linear-static-analysis/ 